\title{
Mutations in PMM2, a phosphomannomutase gene on chromosome 16p13, in carbohydrate-deficient glycoprotein type I syndrome (Jaeken syndrome)
}

Gert Matthijs et al.

Nature Genet. 16, 88-92 (1997).

There is an error in Table 1 on page 88. For families 4, 5, 9, 27, 31 and 41, mutation 2 should read: 425G/A at the nucleotide level, which corresponds to $\mathrm{R} 141 \mathrm{H}$ at the amino acid level. The error does not affect our general conclusions, but results in a different frequency for the mutations $\mathrm{R} 141 \mathrm{H}$ (far more prevalent) and R162W (observed only once, in patient 42). We regret this error.
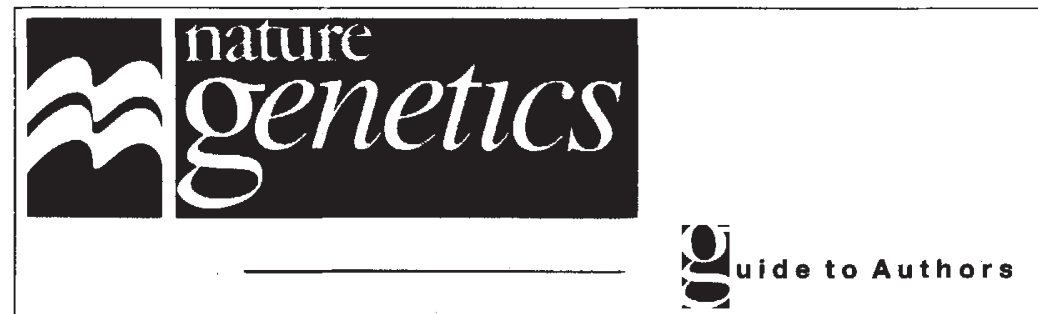

345 park Avenue South

New York, New York

10010

Telephone: 212-726-9314

Fax: 212-545-8341

e-mail: natgen@naturedc.com

Nature Genetics is an international monthly journal publishing exceptional advances in all fields of modern genetic research, with a special emphasis on mammalian genetics and the Genome Project. Manuscripts are selected for publication according to editorial assessment of their general interest and suitability and reports from independent referees. Receipt of all manuscripts will be acknowledged, and those not suitabie for review will be returned immediately. Contributors are welcome to suggest potential reviewers as well as informing the Editor of potential conflicts of interest. Authors of papers previously considered by Nature but ultimately not accepted are welcome to resubmit to Nature Genetics, where they will receive prompt further consideration. Following acceptance of their paper, contributors will receive galley proofs within a few weeks. Contributors will receive a reprint order form with their proofs; reprint orders are processed from our New York office after the manuscript is published and payment received. Nature Genetics does not exact page charges.

\section{Format of Articies}

Manuscripts should be typed, double-spaced, on one side of the paper only. An original and three copies are required, each accompanied by artwork, together with a computer diskette. Reference lists, figure legends and tables should each be on separate sheets, also double-spaced. Please include four copies of any relevant manuscript in press or submitted for publication. Colour prints will be partly paid for by authors unless otherwise agreed. Articles include Summary, introduction, Results and Discussion. There is a separate Methods section following the main text and we include full tities of papers in the reference list. The main text should be between 2,000 and 4,000 words in length. There is a maximum of 8 display items.

Titles should be simple and concise. A brief, accessible Summary of no more than 100 words should explain the rationale and chief conclusions of the work, without references. Results should include short cross-headings to define the main aspects of the study. Authors should deposit sequence data in the databases, and provide an accession number in the paper. The Methods section appears at the end of the text, before the references.

References are numbered sequentially as they appear in the text, followed by those in the figure legends and tables. Do not include any annotation. Full titles of papers are required. All authors should be listed unless there are six or more, in which case 'et al.' should be substituted. First and last page numbers must be included in full; references to books should include publisher, place and date. The list should include only papers published or in press; abstracts, papers submitted or in preparation and personal communications should be cited in the text. (Full details are available in our separate 'Style Guide'.) Figures: Original artwork should be submitted with the manuscript.

\section{Format of Letters}

Nature Genetics also publishes a selection of more concise reports of broad interest to the genetics community. The main Text (excluding legends, references and Methods) is limited to 1,200 words and five display items. There is no abstract: in its place, there is a single paragraph of up to 200 words, with references, containing the essential introductory material and culminating in a brief summary of the results. The remainder of the text is devoted to presenting the results and the principal conclusions of the work. There are no cross-headings. References should be limited to about 30 , but including full titles. Letters also retain a separate Methods section.

Progress, Reviews and Commentary. Nature Genetics publishes a regular series of articles in these categories. Format is essentially that of regular articles, except for a shorter abstract (up to 75 words) and appropriate cross-headings. The journal does consider unsolicited articles.

\section{Submission}

All manuscripts should be sent to the Editor, Nature Genetics, 345 Park Avenue South, New York, New York 10010, USA. (Tel: 212-726-9314; Fax: 212-545-8341; e-mail: natgen@natureny.com). Please provide current fax and phone numbers of the corresponding author on all submissions. DISKETIES. All page proofs are set directly from computer discs provided by the authors. Any common Macintosh or PC word-processing packages (except WordStar or Excel) is compatible and preferable to a text/ASCIl file. Text and figures can aiso be transmitted electronically to our FIP site (Please call for details). 